\title{
Power Displays Between Women and Men in Discussions of Gender-Linked Tasks: A Multichannel Study
}

\author{
John F. Dovidio \\ Colgate University \\ Karen Heltman \\ Colgate University
}

\author{
Clifford E. Brown \\ Wittenberg University \\ Steve L. Ellyson \\ Youngstown State University
}

\author{
Caroline F. Keating \\ Colgate University
}

\begin{abstract}
We conducted a multichannel investigation of how gender-based familiarity moderates verbal and nonverbal behaviors between men and women. Undergraduates in 24 mixed-sex dyads discussed masculine, feminine, and non-gender-linked topics. The primary dependent variables were verbal and nonverbal behaviors related to social power. The verbal behaviors examined were speech initiations and total amount of speech; the nonverbal behaviors studied were visual behavior (while speaking and while listening), gesturing, chin thrusts, and smiling. As expected, systematic differences in the behaviors of men and women emerged on the gender-linked tasks. On the masculine task men displayed more verbal and nonverbal power-related behavior than did women. On the feminine task women exhibited more power than men on most of the verbal and nonverbal measures. Also as predicted, on the non-gender-linked task men displayed greater power both verbally and nonverbally than did women. There were two exceptions to this overall pattern. Across all conditions, women smiled more often than did men, and men had a higher frequency of chin thrusts than did women.
\end{abstract}

In this study we investigated the communication of power between women and men. Social power concerns the ability to influence others or to control the outcomes of others (Ellyson \& Dovidio, 1985). Power is positively related to, but not synonymous with, status and dominance. According to Berger, Wagner, and Zelditch (1985), recognition of status produces

invidious social evaluations (in terms of differences in honor, respect, esteem, etc.) and both specific expectations (capacities to perform specified tasks, such as math problems, mechanical tasks, etc.) and general expectations (capacities which are not defined with respect to tasks, such as "intelligence"). (pp. 12-13)

Thus, status typically implies power. Dominance, like power, relates to the ability to influence or control others, but it also involves "groupness" (Ellyson \& Dovidio, 1985). Specifically, dominance concerns power relationships within a relatively enduring social organization. Thus, although ethological studies of interaction within primate living units may involve domi-

This research was supported by grants from the Colgate University Research Council, from the Colgate Division of Natural Sciences and Mathematics, and from the Faculty Research Fund Board at Wittenberg University.

We are grateful to Mark Gordon, Mark Sibicky, Mary Ellen Snyder, and Frank Wood for their assistance in data collection. We also thank Amy Halberstadt and the reviewers for their helpful criticisms and comments.

Correspondence concerning this article should be addressed to John F. Dovidio, Department of Psychology, Colgate University, Hamilton, New York 13346, or to Clifford E. Brown, Psychology Department, Wittenberg University, Springfield, Ohio 45501. nance, laboratory studies of human interaction are more likely to consider social power.

Sex is a characteristic that has traditionally been related to actual and perceived social power. In the United States, men disproportionately occupy positions of social, political, and economic power relative to women (Basow, 1986). In addition, gender stereotypes characterize men as scoring higher than women on a potency dimension (Ashmore, 1981) and, panculturally, on a strength dimension (Williams \& Best, 1986). Henley (1977) proposed that these power differences are commonly reflected in patterns of communication. Henley and Harmon (1985) asserted that patterns of communication between men and women provide "a micropolitical structure that underlies and supports the macropolitical structure" (p. 152). In support of this argument, Henley (1977) presented evidence of parallel patterns of communication between high- and low-power interactants and between male and female interactants. Our study was therefore designed to examine power-related verbal and nonverbal behavior in mixed-sex interactions.

Berger and his colleagues (Berger, Rosenholtz, \& Zelditch, 1980; Berger et al., 1985), in their expectation states theory, presented a framework that may be useful in understanding how sex and behavioral expressions of power are related in task-oriented situations. Those researchers proposed that because sex has traditionally been correlated with prestige and status differences in society, differential expectations exist concerning the social power of men and women. Berger et al. (1985) defined characteristics of individuals (such as sex or race) that give rise to differential status expectations as diffuse status characteristics. These expectations, in turn, can generalize and, through a 
process of behavioral confirmation of expectancies similar to the self-fulfilling prophecy (Rosenthal \& Jacobson, 1968), affect power-related behavior and perceptions of power across a variety of social contexts (Berger et al., 1985; Eagly, 1983; Meeker \& Weitzel-O'Neill, 1985).

The manner in which sex relates to expressions of power, however, is moderated by the presence or absence of task-relevant cues, cues perceived to be related to the ability to perform the task at hand (Wood \& Karten, 1986). According to expectation states theory, direct information about competence has a greater impact on expectations and behavior than inferences about competence based on diffuse status characteristics. Specifically, when clear cues about competence on a specific task are available, those cues take precedence over diffuse status characteristics and primarily determine expectations, behaviors, and outcomes among interactants. When cues are ambiguous or indicate equivalent competence among interactants, diffuse status characteristics affect expectations and behavior. Thus, recognition of sex and task-relevant information may combine according to a weighted averaging model. More generally, Hembroff and Myers (1984) concluded that information more directly and explicitly related to an assigned task is weighted more heavily in determining outcomes than is information that is only indirectly and implicitly related to ability to perform the task.

In this study we investigated the effect of a task-relevant cue-degree of gender-based familiarity with a discussion topic-on verbal and nonverbal expressions of power between men and women. To the extent that gender-based familiarity relates to bases of social power such as expertise and informedness (French \& Raven, 1959; Raven, 1974), it may affect informational social pressures (Deutsch \& Gerard, 1955). To the extent that gender linkage of the task affects perceptions of socially appropriate behavior, it may affect normative social influence (Deutsch \& Gerard, 1955). Thus, both informational and normative variables could combine to produce differential power displays of men and women interacting on gender-linked tasks. In this study we asked subjects in mixed-sex dyads to describe how to perform (a) automotive oil changing, a task for which men reported greater familiarity than did women; (b) pattern sewing, a task for which women reported greater familiarity than did men; and (c) vegetable gardening, a task for which men and women reported equal familiarity. The primary dependent measures were verbal and nonverbal behaviors that have been shown to be related to social power.

The verbal behaviors we examined were the frequency of speech initiations and the total amount of speech. Previous research has demonstrated that interactants with higher power initiate speech more often (Rosa \& Mazur, 1979) and speak more overall (Bales, 1950; Cappella, 1985; Stein \& Heller, 1979). The nonverbal power-related behaviors studied were percent of time spent looking at the partner while speaking, percent of time spent looking at the partner while listening, rate of gesturing with one's hands, number of chin thrusts, and frequency of smiling. Previous researchers have reported that higher power is communicated by looking more while speaking and less while listening (Dovidio \& Ellyson, 1985; Dovidio, Ellyson, Keating, Heltman, \& Brown, 1988; Ellyson, Dovidio, \& Fehr, 1981; Linkey \& Firestone, 1986); by using more expressive hand gestures during speech (Dittman, 1972; Henley, 1977); by displaying more chin thrusts (Camras, 1980; Henley, 1977); and by nonsmiling poses (Henley, 1977; Keating, 1985) and relatively infrequent smiling behavior (Frieze \& Ramsey, 1976).

Although all of those behaviors have been linked to social power, it should be noted that some of those variables are sensitive both to informational variables, relating to informedness, and to normative variables, associated with social role expectations. That is, in this study, greater task familiarity could provide the subject with more information to talk about, which would involve a greater capacity to participate and perhaps a greater interest in the conversational topic. Nevertheless, the relation between speaking and power is robust (Stein \& Heller, 1979), and when social power is varied in ways unrelated to informedness, higher power people speak more and initiate speech more often than lower power people (Aries, Gold, \& Weigel, 1983; Leffler, Gillespie, \& Conaty, 1982). Lower levels of looking while speaking have been associated with increased task difficulty and related needs to process information (Exline \& Winters, 1965). Other research, however, indicates that persons possessing lower status roles or less dominant personalities look less while speaking than high-status or more dominant persons, independent of task difficulty (Dovidio et al., 1988; Weisfeld \& Linkey, 1985). In addition, gesturing rate could be an indicator of interest in a familiar topic, but it may also be related to dominance and dominance seeking, independent of inherent interest in the topic (Mehrabian \& Williams, 1969). In contrast to these measures, previous research suggests that looking while listening, chin thrusts, and smiling relate to social role relationships, but we are not aware of any studies that demonstrate that these variables are directly affected by informedness.

According to Berger et al. (1985), status in task-oriented groups may be based on actual task competence (informational variables) or on social roles (normative variables). Thus, for both reasons Berger et al. (1985) identified task familiarity as a basis of status in expectation states theory. In this study examination of the patterns of results of the various dependent measures across conditions provides information about the relative impact of informational and normative variables; the results for the non-gender-linked task, because it controlled for informedness, should relate primarily to normative variables.

In addition, some sex differences in nonverbal behavior that are often explained by differential social power may be attributable to differences in other variables such as social tension (Hall \& Halberstadt, 1986). Consequently, we also examined two other nonverbal behaviors that have been related to anxiety, tension, and self-consciousness (see Hall, 1984) but have not been directly related to power. These nonverbal behaviors were laughing and self-touching. Higher levels of laughing and selftouching have been associated with greater nervousness and self-consciousness (Hall, 1984).

We hypothesized that when there is differential familiarity related to the gender linkage of a task, this variable will be the preeminent determinant of power-related behavior. Specifically, we predicted that men would display more verbal and nonverbal indicators of power than would women on the masculine (automotive) task, whereas women would exhibit more powerrelated verbal and nonverbal behaviors on the feminine (sew- 
ing) task. For these two topics normative and informational pressures may both operate to produce systematic differences in power-related behaviors. On the non-gender-linked (gardening) task we predicted that men would exhibit more verbal and nonverbal power signals than would women, because sex serves as a primary status cue when there is no other information indicating competence and power differences among interactants (Berger et al., 1985). As Eagly $(1978,1983)$ has found, sex differences in normative conformity occur even when information is controlled.

In addition, we evaluated the conclusions of previous researchers about the power-related nature of our dependent variables. Harper (1985) observed the following:

Whereas one nonverbal behavior may have several different meanings, depending on the context in which it occurs, its timing and intensity, different sets of nonverbal behaviors in combination may have a convergence in meaning. . . . Given that most research to date has followed a "single-channel" approach in linking specific nonverbal behaviors to dominance and status phenomena, future research must be directed to more complex, subtle behavior patterns. (p. 44)

As Siegman and Feldstein (1985) also noted, a multichannel method makes it possible to study verbal and nonverbal behavior from a functional perspective. In particular, to the extent that the variables hypothesized to be related to power in this study are indeed all power related, they should show similar functional relations to the diffuse status characteristic of sex and to the specific status characteristic of familiarity.

\section{Method}

\section{Overview}

In preliminary testing at the beginning of the term, 88 introductory psychology students rated their familiarity $(0=$ no familiarity, $10=a$ great deal of familiarity) with the materials, steps, and potential problems of 14 activities (e.g., washing and waxing a car, writing a research paper) that varied in their association with masculine and feminine gender roles. On the basis of those anonymous ratings, we selected three tasks as discussion topics: automotive oil changing, for which men showed greater familiarity than did women $(M \mathrm{~s}=7.0 \mathrm{vs.} 2.4, p<.001)$; pattern sewing, for which women showed greater familiarity than did men $(M s=6.4$ vs. 1.4, $p<.001)$; and vegetable gardening, for which men and women indicated equal familiarity $(M s=6.5)$. We drew the 24 men and 24 women who participated in our study from this pool of students. Each mixed-sex dyad discussed the masculine topic (oil changing), the feminine topic (sewing), and the non-gender-linked topic (gardening). The primary dependent variables involved verbal and nonverbal power-related behaviors. The assumption of independence of observations, which is important for most conventional statistical procedures, is likely to be violated when interacting subjects are observed; the behavior of one subject in a dyad depends partly on the behavior of the other subject. Violation of the assumption of the independence of observations generally produces too many Type I errors (Kenny \& Judd, 1986). Thus, in this study, we used the dyad as the unit of analysis.

\section{Subjects}

We randomly selected 24 male and 24 female undergraduates from a pool of 50 male and 38 female students in an introductory psychology class at a midwestern liberal arts college. We randomly paired the sub- jects, who were not previously consociated, in mixed-sex dyads. Participation in this study helped to fulfill their course requirements.

\section{Procedure}

A male or a female experimenter separately escorted the male and female members of the dyad to the research cubicle. After the experimenter seated one member of the dyad behind a removable partition (centered on a table $1 \mathrm{~m}$ in width) that blocked visual contact, the experimenter brought the other member of the dyad into the room and seated him or her at the table, directly across from the first participant. Thus, dyads had no verbal or nonverbal contact before the first discussion task. The removable partition was kept in place at all times except during the 3-min discussions.

Once subjects were seated, they were given the following tape-recorded instructions:

Many tasks share in common three key elements . . . materials, a logical order of steps, and unique problems. . . . In this study, we are concerned with the ways pairs of students communicate these three types of information-materials, steps, and problems-in discussions of various tasks.

The experimenter told the subjects that they would be given a series of 3-min tasks to discuss during the session, that their interactions would be videotaped, and that they were to read and sign an informed consent and video release form. This form indicated that subjects had the right to stop participating at any time and that they retained the right to erase the record of their interaction after participating in the session. All subjects signed the form and participated fully. Throughout the study, concealed video cameras recorded direct, full facial views of each participant. The interactions were recorded using a split-screen image on black and white videotape.

Prior to every discussion, each subject was given an index card indicating the topic to be discussed and emphasizing the points to be covered: materials needed, steps, and potential problems. Subjects were allowed to study the cards for $30 \mathrm{~s}$ before the experimenter removed the partition, signalling the discussion to begin. The experimenter left the room and did not return until a tape-recorded signal indicated the end of the discussion period. The experimenter then returned, replaced the partition, and presented the next topic to be discussed. The order of the three discussion tasks (oil changing, sewing, and gardening) was counterbalanced, and one male and one female experimenter ran two dyads in each order. At the end of the study, the experimenter debriefed the subjects.

Two coders recorded the verbal and nonverbal behaviors from the videotapes. The verbal measures were the number of speech initiations by each participant (Rosa \& Mazur, 1979) and the percent of the total interaction time that each subject spoke (Berger et al., 1985). The nonverbal measures were (a) looking while speaking, the percent of time that the subject looked at his or her partner while the subject spoke (Dovidio \& Ellyson, 1985); (b) looking while listening, the percent of time the subject looked at his or her partner while listening to the partner speak (Dovidio \& Ellyson, 1985); (c) rate of gesturing, the number of expressive hand movements (not in contact with one's own body) that occurred per second while speaking (Dittman, 1972; Henley, 1977); (d) frequency of chin thrusts (Camras, 1980; Henley, 1977); (e) frequency of smiling (Henley, 1977); (f) frequency of self-touching, hand movements in contact with part of one's own body; and ( $\mathrm{g}$ ) frequency of laughing (Henley, 1977; Waxer, 1977).

To establish reliability, before and after viewing the videotapes of interaction during our main study two raters independently coded each of these verbal and nonverbal behaviors during 10 segments from videotapes of pilot research. The interrater reliabilities, based on the intraclass correlation coefficient (and averaged across the before-and-after 
Table 1

Means of Verbal and Nonverbal Measures as a Function of Discussion Topic and Interactant Sex

\begin{tabular}{|c|c|c|c|c|c|c|}
\hline \multirow[b]{2}{*}{ Measure } & \multicolumn{2}{|c|}{$\begin{array}{l}\text { Masculine } \\
\text { topic }\end{array}$} & \multicolumn{2}{|c|}{$\begin{array}{l}\text { Feminine } \\
\text { topic }\end{array}$} & \multicolumn{2}{|c|}{$\begin{array}{l}\text { Non-gender- } \\
\text { linked topic }\end{array}$} \\
\hline & Male & Female & Male & Female & Male & Female \\
\hline \multicolumn{7}{|l|}{ Verbal } \\
\hline $\begin{array}{l}\text { Time speaking } \\
\text { Speech initiations }\end{array}$ & $\begin{array}{l}50 \% \\
14.6\end{array}$ & $\begin{array}{c}18 \% \\
10.7\end{array}$ & $\begin{array}{l}24 \% \\
11.5\end{array}$ & $\begin{array}{l}42 \% \\
14.1\end{array}$ & $\begin{array}{l}45 \% \\
15.8\end{array}$ & $\begin{array}{l}24 \% \\
13.8\end{array}$ \\
\hline \multicolumn{7}{|l|}{ Nonverbal } \\
\hline $\begin{array}{l}\text { Looking while } \\
\text { speaking } \\
\text { Looking while }\end{array}$ & $47 \%$ & $22 \%$ & $19 \%$ & $40 \%$ & $36 \%$ & $29 \%$ \\
\hline listening & $26 \%$ & $81 \%$ & $71 \%$ & $32 \%$ & $36 \%$ & $63 \%$ \\
\hline Rate of gesturing & .14 & .03 & .04 & .09 & .09 & .03 \\
\hline $\begin{array}{l}\text { thrusts } \\
\text { Frequency of }\end{array}$ & 1.88 & 0.20 & 1.45 & 0.21 & 1.54 & 0.38 \\
\hline $\begin{array}{l}\text { smiling } \\
\text { Frequency }\end{array}$ & 10.1 & 14.4 & 12.5 & 14.4 & 9.1 & 12.0 \\
\hline touching & 6.3 & 6.5 & 5.9 & 6.8 & 6.2 & 6.3 \\
\hline $\begin{array}{l}\text { Frequency of } \\
\text { laughing }\end{array}$ & 3.9 & 6.0 & 4.4 & 6.6 & 3.9 & 5.4 \\
\hline
\end{tabular}

time periods), were .94 for the number of speech initiations, .95 for the amount of speech, .86 for looking while speaking, .95 for looking while listening, .93 for gesturing, .66 for chin thrusts, .98 for smiling, .86 for self-touching, and .88 for laughing. For the actual sessions, one rater coded at different times the number of speech initiations, the amount of speech, gesturing, and self-touching. The other rater coded visual behavior, smiling, laughing, and chin thrusts. Both raters were unaware of the hypotheses.

\section{Results}

We performed preliminary multivariate analyses of variance (MANOVAS)-Sex of Interactant (within dyad) $\times$ Topic ( 3 levels) $\times$ Topic Order (6 levels) $\times$ Experimenter Sex-separately for the verbal measures, the power-related nonverbal behaviors, and the non-power-related nonverbal measures. The analyses revealed no significant main effects or interactions associated with the order of the tasks or the sex of the experimenter. Consequently, we did not include these variables in subsequent analyses. The means as a function of sex of interactant and topic for each measure are presented in Table 1.

\section{Verbal Measures}

The 2 (sex of interactant, within dyad) $\times 3$ (topic) repeated measures MANOVA of the two verbal measures (percent of time spent speaking and frequency of speech initiations) revealed a main effect for sex, $F_{\mathrm{m}}(2,22)=3.62, p<.044$. However, a significant Sex $\times$ Topic multivariate interaction, $F_{\mathrm{m}}(4,92)=$ $12.03, p<.001$, suggested that topic was an important moderator of sex differences. Significant Sex $\times$ Topic interactions were also revealed in the univariate analyses of variance (ANOVAs) of the amount of speech, $F(2,46)=32.84, p<.001$, and the frequency of speech initiations, $F(2,46)=25.04, p<.001$.

To interpret the moderating role of topic, we examined the simple effect of sex separately for the masculine, feminine, and the non-gender-linked tasks. The results of the simple effects analyses for both verbal and nonverbal measures are presented in Table 2. As predicted, we obtained significant effects for sex for both the masculine and feminine tasks. On the masculine task, men spoke a greater amount of time and initiated speech more often than did women; on the feminine task, women held the floor longer and initiated speech more often than did men (see Table 1).

For the non-gender-linked (gardening) task (see Table 2), we obtained a multivariate effect for sex. Men spoke for a significantly longer time than did women and tended to initiate speech more often (see Table 1). Thus, consistent with expectation states theory, men engaged in more power-related verbal behavior than did women on the masculine task, whereas women displayed greater power verbally than did men on the feminine task. When differential familiarity with the task did not exist, as in the non-gender-linked task, men displayed greater verbal power-related behavior than did women.

\section{Nonverbal Measures}

Power-related variables. The MANOVA of the nonverbal power-related measures revealed main effects for both sex, $F_{\mathrm{m}}(5$, $19)=6.07, p<.022$, and topic, $F_{\mathrm{m}}(10,86)=2.80, p<.005$. These effects, however, were moderated by a Sex $\times$ Topic interaction, $F_{\mathrm{m}}(10,86)=5.84, p<.001$. We obtained significant univariate interactions on all five measures: looking while speaking, $F(2,46)=21.01, p<.001$; looking while listening, $F(2,46)=61.03, p<.001$; rate of gesturing, $F(2,46)=14.85$, $p<.001$; frequency of chin thrusts, $F(2,46)=3.30, p<.046$; and smiling, $F(2,46)=6.91, p<.002$ (see Table 1 for means). Following the analysis of the verbal measures, we assessed the effect of sex separately for the three topic conditions.

Table 2

Separate Tests of Sex Differences in Verbal and Nonverbal Power-Related Behaviors for the Masculine, Feminine, and Non-Gender-Linked Topics

\begin{tabular}{|c|c|c|c|c|c|c|}
\hline \multirow[b]{2}{*}{ Measure } & \multicolumn{2}{|c|}{$\begin{array}{l}\text { Masculine } \\
\text { topic }\end{array}$} & \multicolumn{2}{|c|}{$\begin{array}{l}\text { Feminine } \\
\text { topic }\end{array}$} & \multicolumn{2}{|c|}{$\begin{array}{l}\text { Non-gender- } \\
\text { linked topic }\end{array}$} \\
\hline & $F$ & $p$ & $F$ & $p$ & $F$ & $p$ \\
\hline Verbal $^{a}$ & 15.16 & .001 & 5.23 & .014 & 7.40 & .003 \\
\hline Time spe & 28.59 & .001 & 9.9 & .004 & 14.64 & .001 \\
\hline Speech i & 17.01 & .001 & 5.58 & .027 & 2.94 & .100 \\
\hline Nonvert & 13.16 & .001 & 6.37 & .001 & 7.10 & .001 \\
\hline $\begin{array}{l}\text { Looking while } \\
\text { speaking }\end{array}$ & 10.49 & .001 & 17.24 & .001 & 0.83 & .372 \\
\hline Looking while & & & & & & \\
\hline listening & 34.41 & .001 & 12.62 & .002 & 8.47 & .008 \\
\hline Rate of gesturing & 10.74 & .003 & 5.55 & .027 & 9.70 & .005 \\
\hline $\begin{array}{l}\text { Frequency of chin } \\
\text { thrusts }\end{array}$ & 22.11 & .001 & 2.27 & .145 & 16.57 & .001 \\
\hline $\begin{array}{l}\text { Frequency of } \\
\text { smiling }\end{array}$ & 31.58 & .001 & 4.59 & .043 & 10.22 & .004 \\
\hline
\end{tabular}

Note. For tests of the univariate effects, $d / s=1,23$.

${ }^{2}$ For the multivariate effects for verbal behavior, $d / \mathrm{s}$ for $F_{\mathrm{m}}=2,22$.

${ }^{b}$ For the multivariate effects for nonverbal behavior, $d / \mathrm{s}$ for $F_{\mathrm{m}}=5,19$. 
For the masculine task (see Table 2), we obtained a multivariate effect for sex and significant univariate effects on all five measures: looking while speaking, looking while listening, gesturing, chin thrusts, and smiling. As predicted, on the masculine task, men looked more while speaking and less while listening, gestured more, displayed more chin thrusts, and smiled less frequently than did women (see means in Table 1).

For the feminine task (see Table 2), we also obtained a multivariate main effect for sex and univariate effects on four of the measures: looking while speaking, looking while listening, gesturing, and smiling. As predicted, women looked more while speaking and less while listening, and they gestured more than did men (see Table 1). However, although the differences were less pronounced than for the masculine task, women smiled more often than did men and tended to display fewer chin thrusts. The results for smiling and chin thrusts were not consistent with predictions.

For the non-gender-linked task (see Table 2), we obtained a multivariate main effect for sex. We found significant univariate effects on four of the measures: looking while listening, gesturing, chin thrusts, and smiling. As expected, men looked less while listening, gestured more, displayed more chin thrusts, and smiled less than did women. Men looked somewhat more, but not significantly, while speaking than did women (see Table 1). In general, though, when task familiarity was equivalent, men showed higher levels of the nonverbal power-related behaviors than did women.

Non-power-related measures. The interaction pattern obtained for the power-related verbal and nonverbal behaviors cannot easily be accounted for solely in terms of self-consciousness or social tension as expressed in self-touching or laughter. The 2 (sex) $\times 3$ (topic) repeated measures MANOva we performed on self-touching and laughing (see Table 1 for means) revealed only a main effect for sex, $F(2,22)=5.23, p<.014$. ANOVAS indicated that women laughed more frequently than did men, $F(1,23)=10.38, p<.004$, but that there was no reliable difference between women and men in the frequency of self-touching behaviors, $F<1$. The multivariate and univariate Sex $\times$ Topic interactions did not approach significance (all $p s>.48$ ).

\section{Factor Analysis of Dependent Measures}

In this study, we classified the dependent variables a priori on the basis of theory and research linking or not linking them with social power. To evaluate our assumptions, we performed a factor analysis using varimax rotation on the dependent measures. Because of the interrelationships between the behaviors of interacting dyad members and the repeated measures nature of the design, we calculated this factor analysis on the matrix of residual values created by removing the common variance associated with these effects (see Cohen \& Cohen, 1983, pp. $490-500$ ). We obtained three factors (eigenvalues $>1.00$ ). Five of the seven variables hypothesized to be power related loaded on the same factor. These variables were amount of speech (loading $=.92$ ), number of speech initiations (loading $=.70$ ), rate of gesturing (loading $=.73$ ), looking while speaking (loading $=.70$ ), and looking while listening (loading $=-.83$ ). Smiling, which was hypothesized to be related to power, loaded with laughing on a second factor (loadings $=.80$ and .74 ). This factor may represent nervousness; previous research has indicated that laughing and smiling often co-occur and that both can reflect anxiousness (Hall, 1984, 1985). Chin thrusts, another variable hypothesized to relate to power, loaded negatively and less strongly on this dimension (loading $=-.51$ ). The third factor was composed only of self-touching (loading $=.94$ ). Factor analyses performed separately for male and female interactants revealed similar factor structures. Overall, the factor structure that we obtained generally provides support for our assumptions and cannot be accounted for in terms of simply speaking versus listening behaviors.

\section{Discussion}

Overall, the results of our study are consistent with the Berger et al. (1985) expectation states theory. Sex differences in powerrelated behavior were affected by context. According to Berger et al. (1985), when information about perceived competence (e.g., relating to familiarity) is available, this information should be the primary determinant of power-related behaviors. We found that systematic differences in the power-related behaviors of men and women emerged in the situations in which there was differential familiarity based on the gender-linked nature of the task. Furthermore, consistent with expectation states theory, during the non-gender-linked topic, sex, presumably operating as a diffuse status characteristic, was systematically related to power-related behavior.

In general, expectation states theory seems to provide the most parsimonious explanation for the results we obtained. Differences in informedness between participants can explain the results on the gender-linked tasks but cannot account for the differences between men and women on the non-gender-linked task, on which informedness was equivalent between the sexes. Differences in the repertoire of male and female nonverbal behavior as the result of socialization can explain the data for the non-gender-linked task but cannot easily account for the situational effects of the gender-linked tasks. Although expectation states theory does not generally distinguish between informational (e.g., relating to informedness) and normative (e.g., social role) determinants of power, it does successfully predict the overall pattern of results we obtained.

In addition, the pattern of findings generally supports a weighted averaging model of task-relevant and diffuse status cues. First, both sex and gender-linked familiarity affected power-related behavior. The MANOVAs revealed stronger sex differences for both verbal and nonverbal power-related measures on the masculine task, on which familiarity and sex effects were hypothesized to operate in the same direction, than on the feminine task, on which familiarity and sex effects were presumed to exert opposing influences. For the five behaviors-amount of speech, number of speech initiations, rate of gesturing, looking while speaking, and looking while listening - that showed the predicted interaction pattern, the average proportion of variance accounted for by sex tended to be greater for the masculine task (.31) than for the feminine task (.18). For the non-genderlinked task, the average proportion of variance accounted for was .13. Second, when there were opposing forces, the task-relevant cue of familiarity had a greater impact on power-related 
behavior than did the diffuse status characteristic of sex. On the feminine task, women showed higher levels of power than men on the same five measures. Because the pilot research indicated that the masculine and feminine tasks were equivalently gender linked, these results suggest that sex and task familiarity combined to affect power-related behaviors.

Our finding that both sex and gender-based familiarity combined in a weighted fashion does not necessarily contradict previous research that demonstrates that competence information can eliminate sex differences (Freese \& Cohen, 1973). Hembroff and Myers (1984) found that factor weights are related to their degree of task relevance. In our study, the gender association of the task provided indirect information about competence. Specifically, it provided subjects with a basis for inferring the relative ability of male and female interactants. It is possible that more explicit information about the competence of specific interactants could override sex differences completely (cf. Wood \& Karten, 1986).

It is important to note that although most of the behaviors we studied fall into the Berger et al. (1985) category of expressive task cues, many of the behaviors can be, and frequently are, determined by other variables. Affiliative desires, social tension, and cognitive variables, as well as social power, can affect the behaviors. With respect to the nonverbal measures in this study, visual behavior has been related to affiliative needs (Exline, 1963), anxiety (Fugita, 1974), and cognitive demand (Exline \& Winters, 1965); gesturing is a behavior that supplements and adds emphasis to spoken words (Ekman \& Friesen, 1969); and smiling has been related to social tension (Hall \& Halberstadt, 1986), nervousness (Frances, 1979), approval seeking (Rosenfeld, 1966), friendliness (Halberstadt \& Saitta, 1987; Kraut \& Johnston, 1979), and femininity (Halberstadt \& Saitta, 1987). In many instances, of course, it is possible that power, affiliative motives, approval seeking, and social tension may be interrelated. Nevertheless, it is also possible that those variables can produce independent effects on behavior.

We therefore also evaluated the assumption, derived from previous research, that our a priori classification of power-related variables was valid. If these variables are in fact mainly determined by power, then they should (a) be related to the same underlying dimension and (b) respond to the power-related independent variables in systematic and predictable ways. Support for the first issue comes from the finding of the factor analysis that five of the seven variables hypothesized to be power related loaded on the same dimension and that none of the nonpower-related behaviors loaded highly on this factor. Smiling and chin thrusts were the two variables hypothesized to be related to power that did not load as expected. Support for the second issue comes from the results of the ANOVA. Five of the seven variables hypothesized to be power related showed the predicted interaction patterns, whereas the two measures assumed not to be power related (laughing and self-touching) demonstrated a different pattern. Among the power-related variables, smiling and chin thrusts were again the exceptions.

With regard to smiling, women smiled more than did men in all conditions. This finding is consistent with Hall's (1985) review of the literature indicating that in $92 \%$ of the tests (total $n=19$ ) of sex differences in adults, women smiled more frequently than did men. Supporting our predictions, the greatest and least differences in smiling occurred for the masculine and feminine topics, respectively. Nevertheless, the individual means for male and female interactants were inconsistent with predictions. Men smiled more often on the feminine task than on the masculine task (as predicted), but women smiled equally often across those topics.

One possible explanation for these results is that smiling has different meanings for men and women (Frances, 1979; Halberstadt \& Saitta, 1987), Our results, however, do not provide much support for this position; for men and women, smiling loaded similarly in the factor analysis. Another possibility, noted by Hall (1985), is that smiling may have various meanings and purposes: a reflection of nervousness, pleasure, an attempt to please or appease, or an indication of subordination. Thus, the higher frequency and lower variability of smiling across conditions displayed by women could also reflect the women's generally higher levels of social tension in the situation (Hall \& Halberstadt, 1986). The finding that smiling and laughing, although measured separately, loaded on the same factor supports this interpretation. It is also possible that the pattern of means for smiling may be attributable to gender differences in socialization, which may be unrelated to social power. LaFrance and Carmen (1980) and Miller, Dovidio, and Keating (1984), for example, have found that sex differences in smiling were more pronounced for traditionally sex-typed men and women than for androgynous men and women. Sex-typed women consistently showed the highest level of smiling. In addition, our finding that smiling did not load on the power dimension for either men or women questions the link between power and smiling proposed by other researchers (e.g., Henley, 1977).

The meaning of the pattern of results for chin thrusts, particularly the consistently higher level for men than women, is not entirely clear; research on chin thrusts in humans is limited (see Camras, 1980). It is possible that the role as well as the behavior of chin thrusts may be different for men than for women. In nonhuman primates there is evidence that chin thrusts are part of a male dominance display (Camras, 1980), but there is also evidence that females achieve dominance in different ways than do males (Shively, 1985). Thus, if there is a phylogenetic basis for chin thrusts, as some researchers suggest (see Camras, 1980), then, on the basis of the research on dominance signals between male nonhuman primates, it is possible that chin thrusts may be primarily a male power behavior. Our finding that chin thrusts did not load on the power factor for either men or women weakens this argument, however. Alternatively, it is possible that higher levels of self-consciousness of female than of male interactants generally inhibited women's body movements and thus reduced the frequency and variability of chin thrusts. This interpretation is consistent with the finding that for men and women separately, chin thrusts and self-touching loaded on the same factor. The analysis of self-touching alone did not reveal overall differences by sex, but the MANOVA of self-touching and chin thrusts did. The role of differential socialization of men and women, of course, also cannot be ruled out. Thus, our study suggests the complexity of our dependent measures and indicates the importance of multichannel research. Further study of the interrelations among various verbal and nonverbal behaviors could help identify the underlying dimensions of these expressions. 
Not only are the dependent measures in this research potentially related to several variables, but the conceptual independent variable of power is also complex (see Ellyson \& Dovidio, 1985). French and Raven (1959; Raven, 1974) have identified several sources of social power: informational power, related to the quality and amount of information a person possesses; expert power, based on the belief that a person is knowledgeable; legitimate power, based on the shared recognition of an authority structure; and coercive and reward power, related to the ability to mediate punishments and positive outcomes. Our familiarity manipulation likely involved informational power, expert power, and perhaps even legitimate power. Each of the sources of power identified by French and Raven (1959) may be characterized by a different constellation of cognitive (e.g., relating to perceived task difficulty), affective (e.g., relating to tension), and social (e.g., relating to affiliative motives) variables. Consequently, a fuller understanding of the effects of social power on nonverbal behavior requires conceptual replication in which power is operationalized in various ways across studies.

Finally, the social significance of the sex differences in verbal and nonverbal behavior that occurred when task familiarity was equivalent should not be overlooked. Whether the original cause is the historical subordination of women (Henley, 1977), associations based on the existing distribution of roles in contemporary society (Berger et al., 1985; Eagly, 1983), or differences in gender role socialization that are unrelated to power, during interaction these gender differences may systematically communicate information about relative power (Dovidio \& Ellyson, 1982). Furthermore, these messages may be sent and received without the conscious awareness of participants (Berger et al., 1985; Mayo \& Henley, 1981; Rosa \& Mazur, 1979). Thus, nonverbal sex and gender differences in behavior may be subtle but significant variables in shaping power relationships between women and men. The finding that task familiarity was the predominant determinant of power-related behavior in this study suggests, however, that a little knowledge may be a valuable thing for eliminating conscious and nonconscious sex bias.

\section{References}

Aries, E. J., Gold, C., \& Weigel, R. H. (1983). Dispositional and situational influences on dominance behavior in small groups. Journal of Personality and Social Psychology, 44, 779-786.

Ashmore, R. D. (1981). Sex stereotypes and implicit personality theory. In D. L. Hamilton (Ed.), Cognitive processes in stereotyping and intergroup behavior (pp. 37-81). Hillsdale, NJ: Erlbaum.

Bales, R. (1950). Interaction process analysis. Reading, MA: AddisonWesley.

Basow, S. A. (1986). Sex-role stereotypes: Traditions and alternatives (2nd ed.). Monterey, CA: Brooks/Cole.

Berger, J., Rosenholtz, S. J., \& Zelditch, M., Jr. (1980). Status organizing processes. Annual Review of Sociology, 6, 479-508.

Berger, J., Wagner, D. G., \& Zelditch, M., Jr. (1985). Introduction: Expectation states theory. In J. Berger \& M. Zelditch, Jr. (Eds.), Status, rewards, and influence (pp. 1-72). San Francisco: Jossey-Bass.

Camras, L. (1980). Animal threat displays and children's facial expressions: A comparison. In D. R. Omark, F. F. Strayer, \& D. G. Freedman (Eds.), Dominance relations: An ethological view of human conflict and social interaction (pp. 121-136). New York: Garland STPM Press.

Cappella, J. N. (1985). Controlling the floor in conversation. In A. W.
Siegman \& S. Feldstein (Eds.), Multichannel integrations of nonverbal behavior (pp. 69-103). Hillsdale, NJ: ErIbaum.

Cohen, J., \& Cohen, P. (1983). Applied multiple regression/correlational analysis for the behavioral sciences ( $2 \mathrm{nd}$ ed.). Hillsdale, $\mathrm{NJ}$ : Erlbaum.

Deutsch, M., \& Gerard, H. (1955). A study of normative and informational influence upon individual judgment. Journal of Abnormal and Social Psychology, 51, 629-636.

Dittman, A. T. (1972). Interpersonal messages of emotion. New York: Springer Publishing.

Dovidio, J. F., \& Ellyson, S. L. (1982). Decoding visual dominance behavior: Attributions of power based on the relative percentages of looking while speaking and looking while listening. Social Psychology Quarterly, 45, 106-113.

Dovidio, J. F., \& Ellyson, S. L. (1985). Patterns of visual dominance behavior in humans. In S. L. Ellyson \& J. F. Dovidio (Eds.), Power, dominance, and nonverbal behavior (pp. 129-149). New York: Springer-Verlag.

Dovidio, J. F., Ellyson, S. L., Keating, C. F., Heltman, K., \& Brown, C. E. (1988). The relationship of social power to visual displays of dominance between men and women. Journal of Personality and Social Psychology, 54, 233-242.

Eagly, A. H. (1978). Sex differences and influenceability. Psychological Bulletin, 85, 86-116.

Eagly, A. H. (1983). Gender and social influence: A social psychological analysis. American Psychologist, 38, 971-981.

Ekman, P., \& Friesen, W. V. (1969). The repertoire of nonverbal behavior: Categories, usage, and coding. Semiotica, 1, 49-98.

Ellyson, S. L., \& Dovidio, J. F. (1985). Power, dominance, and nonverbal behavior: Basic concepts and issues. In S. L. Ellyson \& J. F. Dovidio (Eds.), Power, dominance, and nonverbal behavior (pp. 1-27). New York: Springer-Verlag.

Ellyson, S. L., Dovidio, J. F., \& Fehr, B. J. (1981). Visual behavior and dominance in women and men. In C. Mayo \& N. M. Henley (Eds.), Gender and nonverbal behavior (pp. 63-79). New York: Springer-Verlag.

Exline, R. V. (1963). Explorations in the process of person perception: Visual interaction in relation to competition, sex, and need for affiliation. Journal of Personality; 31, 1-20.

Exline, R. V., \& Winters, L. C. (1965, April). Effects of cognitive diffculty and cognitive style upon eye to eye contact in interviews. Paper presented at the annual meeting of the Eastern Psychological Association, Philadelphia, PA.

Frances, S. J. (1979). Sex differences in nonverbal behavior. Sex Roles, $5,519-535$.

Freese, L., \& Cohen, B. P. (1973). Eliminating status generalization. Sociometry, 36, 177-193.

French, J. R. P., Jr., \& Raven, B. H. (1959). The bases of social power. In D. Cartwright (Ed.), Studies in social power (pp. 150-167). Ann Arbor: University of Michigan Press.

Frieze, I. H., \& Ramsey, S. J. (1976). Nonverbal maintenance of traditional sex roles. Journal of Social Issues, 32, 133-141.

Fugita, S. S. (1974). Effects of anxiety and approval on visual interaction. Journal of Personality and Social Psychology, 29, 586-592.

Halberstadt, A. G., \& Saitta, M. B. (1987). Gender, nonverbal behavior, and perceived dominance: A test of the theory. Journal of Personality and Social Psychology, 53, 257-272.

Hall, J. A. (1984). Nonverbal sex differences: Communication accuracy and expressive style. Baltimore, MD: Johns Hopkins University Press.

Hall, J. A. (1985). Male and female nonverbal behavior. In A. W. Siegman \& S. Feldstein (Eds.), Multichannel integrations of nonverbal behavior (pp. 195-225). Hillsdale, NJ: Erlbaum.

Hall, J. A., \& Halberstadt, A. G. (1986). Smiling and gazing. In J. S. 
Hyde \& M. Linn (Eds.), The psychology of gender: Advances through meta-analysis (pp. 136-158). Baltimore, MD: Johns Hopkins University Press.

Harper, R. G. (1985). Power, dominance, and nonverbal behavior: An overview. In S. L. Ellyson \& J. F. Dovidio (Eds.), Power, dominance, and nonverbal behavior (pp. 29-48). New York: Springer-Verlag.

Hembroff, L. A., \& Myers, D. E. (1984). Status characteristics: Degrees of task relevance and the decision process. Social Psychology Quarterly, 47, 337-346.

Henley, N. M. (1977). Body politics: Power, sex, and nonverbal communication. Englewood Cliffs, NJ: Prentice-Hall.

Henley, N. M., \& Harmon, S. (1985). The nonverbal semantics of power and gender: A perceptual study. In S. L. Ellyson \& J. F. Dovidio (Eds.), Power, dominance, and nonverbal behavior (pp. 151-164). New York: Springer-Verlag.

Keating, C. F. (1985). Human dominance signals: The primate in us. In S. L. Ellyson \& J. F. Dovidio (Eds.), Power, dominance, and nonverbal behavior (pp. 89-108). New York: Springer-Verlag.

Kenny, D. A., \& Judd, C. M. (1986). Consequences of violating the independence assumption in analysis of variance. Psychological Bulletin, 99, 422-431.

Kraut, R. E., \& Johnston, R. E. (1979). Social and emotional messages of smiling: An ethological approach. Journal of Personality and $S o-$ cial Psychology, 37, 1539-1553.

LaFrance, M., \& Carmen, B. (1980). The nonverbal display of psychological androgyny. Journal of Personality and Social Psychology, 38, $36-49$.

Leffler, A., Gillespie, D. L., \& Conaty, J. C. (1982). The effects of status differentiation on nonverbal behavior. Social Psychology Quarterly, 45, 153-161.

Linkey, H. E., \& Firestone, I. J. (1986, August). Dominance: Nonverbal behaviors, personality trait, and interaction outcomes. Paper presented at the 94th Annual Convention of the American Psychological Association, Washington, DC.

Mayo, C., \& Henley, N. M. (1981). Nonverbal behavior: Barrier or agent for sex role change? In C. Mayo \& N. M. Henley (Eds.), Gender and nonverbal behavior (pp. 3-13). New York: Springer-Verlag.

Meeker, B. F., \& Weitzel-O'Neill, P. A. (1985). Sex roles and interpersonal behavior in task-oriented groups. In J. Berger \& M. Zelditch, Jr. (Eds.), Status, rewards, and influence (pp. 379-405). San Francisco: Jossey-Bass.

Mehrabian, A. H., \& Williams, M. (1969). Nonverbal concomitants of perceived and intended persuasiveness. Journal of Personality and Social Psychology, 13, 37-58.

Miller, L., Dovidio, J. F., \& Keating, C. F. (1984, April). Status, gender, and smiling. Paper presented at the annual meeting of the Eastern Psychological Association, Baltimore, MD.

Raven, B. H. (1974). The comparative analysis of power and preference. In J. Tedeschi (Ed.), Perspectives on social power (pp. 150-167). Chicago: Aldine.

Rosa, E., \& Mazur, A. (1979). Incipient status in small groups. Social Forces, 58, 18-37.

Rosenfeld, H. M. (1966). Approval-seeking and approval-inducing functions of verbal and nonverbal responses in the dyad. Journal of Personality and Social Psychology, 4, 597-605.

Rosenthal, R., \& Jacobson, L. (1968). Pygmalion in the classroom. New York: Holt, Rinehart \& Winston.

Shively, C. (1985). The evolution of dominance hierarchies in nonhuman primate society. In S. L. Ellyson \& J. F. Dovidio (Eds.), Power, dominance, and nonverbal behavior (pp. 67-87). New York: SpringerVerlag.

Siegman, A. W., \& Feldstein, S. (1985). Prologue. In A. W. Siegman \& S. Feldstein (Eds.), Multichannel integrations of nonverbal behavior (pp. xii-xxiv). Hillsdale, NJ: Erlbaum.

Stein, R. T., \& Heller, T. (1979). An empirical analysis of the correlations between leadership status and participation rates reported in the literature. Journal of Personality and Social Psychology, 37, 19932002.

Waxer, P. H. (1977). Nonverbal cues for anxiety: An examination of emotional leakage. Journal of Abnormal Psychology, 86, 306-314.

Weisfeld, G. E., \& Linkey, H. E. (1985). Dominance displays as indicators of a social success motive. In S. L. Ellyson \& J. F. Dovidio (Eds.), Power, dominance, and nonverbal behavior (pp. 109-128). New York: Springer-Verlag.

Williams, J. E., \& Best, D. L. (1986). Sex stereotypes and intergroup relations. In S. Worchel \& W. G. Austin (Eds.), Psychology of intergroup relations (pp. 244-259). Chicago: Nelson-Hall.

Wood, W., \& Karten, S. J. (1986). Sex differences in interaction style as a product of perceived sex differences in competence. Journal of Personality and Social Psychology, 50, 341-347.

Received July 8, 1987

Revision received February 9, 1988

Accepted May 25, 1988

\section{APA Convention "Call for Programs"}

The "Call for Programs" for the 1989 annual APA convention will be included in the October issue of the APA Monitor. The 1989 convention will be in New Orleans, Louisiana, from August 11 through 15. Deadline for submission of program and presentation proposals is December 15,1988 . This earlier deadline is required because many university and college campuses will close for the holidays in mid-December and because the convention is in mid-August. Additional copies of the "Call" will be available from the APA Convention Office in October. 